\section{A2 ote}

\author{
ox
}

\section{THE PREPARATION OF CATGUT FOR SURGICAL PURPOSES. \\ BY LORD LISTER, F.R.S.}

CatadT used for ligatures or sutures in surgery should fulfil various conditions. It should, after sosking in water or blood serum, be strong enough to bear sing strain to which it may be subjectel, and should hold perfectly when tied in a reef knot. It must not be so rlgid as 1 t lies among the tissues as to have any chance of working its way out by mechanical Irritation. Nor should $1 t$ be too quickly absorbed, but should be consumed so elowly by the cells of the new tlssue that grows at its expense that, in case of the ligature of an arterial trunk in Its continulty, it may serve sufficiently long as a support for the aubstitute living thread in its embryonic condition. At the same time, it is essential that the catgat be securejy aseptic when applied.

Of the varions anbstances which I have tried for the preparation of catgut, that which has, with one exception, most nearly approached the Ideal is sulphate of chromium. The one exception is secure asepsis of the gut substance, this salt belng utterly untrustwortby as a germiclde; this defect is easily remedied by the addition of a little corrosive aublimate, the powerful germicidal action of which is not prevented by the chromium sulphate.

I was at one time discouraged from using chromium oulphate by finding that it varied extremely in quality according to the manulacturer who supplied it. Thas one sample got from a well known firm proved quite insolnble In water.* But a perfectly satisfactiory result was obtained by adding solution of sulphurous acid (P.B.) to solution of chromic acid until the rich orange-brown of the latter has passed through grass-green to the pure blue of chromlum sulphate. When this has occurred no more should be added, since free sulphurous acld produces a precipitate with bichloride of mercury, and would thus, in proportion to its amount, withdraw the germicide from solution when the two liquids are mixed. In order to make quite sure that no free enlphurous acid is present, it is well to keep a few drops of the chromic acid liquid in reserve, and add them when the blue colour has appeared, so as to restore the green tint.

Another point that requires attention arises from the fact that the P.B. solution of sulphurous acid, as obtained from the chemist, is generally somewhat deficient in the amount ol $\mathrm{SO}_{2}$, in consequence of loss by volatilization. Hence it is necessary to use a smaller quantity of water for dissolving the chromic acid than would otherwise be used; and when the proper tint has been got, add enough distilled water to bring the liquld to the regulsite measure.

The following directions for preparing what is known as chromic (or sometimes eulpho-chromlc) catgut in accordance with the above conditions were given to mana. facturing chemists in 1894, bat have never yet been published :

"The preparing liquid must be twenty times the welght of the catgut. So for 40 grains of catgut 800 grains of preparing liquid are required. It is made by mixlng two liquids-namely, the chromium sulphate liquid and the sublimate liquid.

"The sublimate liquid is:

Corrosive sublimate Distllled water ....

$$
\begin{array}{lll}
2 & 2 \\
\cdots & \cdots & 320
\end{array}
$$

"The sublimate may be dissolved by heat, but the solution must be used cold.

"The chromlum sulphate liquid is prepared thus :

$$
\text { Chromic acld } \quad \ldots \quad \ldots \quad \ldots \quad 4 \text { grains }
$$$$
\text { Distilled water } \quad \ldots \quad \ldots . \quad \ldots \quad 240 \text {, }
$$

"Add to this as much sulphurous acld (P.B. solution) as gives a green colour. If more is added the colour becomes

* Ilearn from Messrs. Morson (of Elm Street, Gray's Inn lioad), who to this salt that ita most suit able form requires very great care in its preparation in order to avoid variation in its composition, and also that it is extremely hygroscopic, so that, unless it is very carefully preserved, water in variable amount becomes associated with it, another cause of uncertinty in its composition. blue, which shows that rather too much sulphurous acid has been used. It is well to reserve a few drops of the chromic acid solution, to be added after the blue colour has jast appeared and restore it to green. Then enough distilled water is added to bring the green llquid up to 480 grains. Then add the sublimate llquid."

The catgut is kept twenty-four hours in the preparing liguld, and is then dried on the stretch.

N.B.-It is essentlal that the $\mathrm{OrO}_{3}$ and $\mathrm{SO}_{2}$ solutions be mixed before the $\mathrm{HgCl}_{2}$ solution is added.

Catgut prepared in this way remains actively antiseptic in its substance for an indefinite period, as was shown by the inllowing experiment:

Some slender hanks prepared three years previously, welghlng 207 grains, chopped into short segments, were placed in a small mortar and treated with enough distilled water to cover them, 2,000 grains belng required for the purpose. The gat was then pressed firmly with a pestle, and the same was afterwards done three times at intervals of about three hours. The gut and water were then trans: ferred to a stoppered bottle for seventeen hours, when the liquid was poured off and filtered, being clear and almost colourless.

The germicidal property of the infusion was carelully tested by the late Dr. Allan Macfadyen. In spite of the large amount of water used in preparing it, be lound that it destroyed the Sireptococcus pyogenes in a quarter of an hour. When diminished to half its bulk. by evaporation in vacuo it killed Staphylccoccus pyogenes aureus in half an hour; and when larther reduced by one-hall it deprived the resisting spores of anthrax of vitality in two hours, although the amount of the liquid was still about twice that of the catgut to which it was applied.

The following is Dr. Macfadsen's account of these experiments :

$$
\text { Iiquid Tested. }
$$

Infusion of chromic catgut $=100 \mathrm{c.cm}$.

\section{Organisms Used.}

Bacillus anthracis, sporing potato culture.

Staphyloccus pyogenes aureus, laboratory stock cultare.

Streptococcus pyogen es, virulent culture.

\section{Methods.}

Threads were roaked in emulsions of the sbove organisms and exposed to the action of the above liquids for varying periods of time-fifteen minutes to two hours. The tbreads were then washed in (1) sulphide of ammonium, (2) distilled water (oterlle), and placed on sloping agar and glycerine agar at blood heat fcr seventy-two hours.

\begin{tabular}{|c|c|c|c|c|c|c|c|c|}
\hline \multicolumn{5}{|c|}{ Time. } & $\frac{1}{\$}$ Hour. & $\frac{1}{2}$ Hour. & 1 Hour. & 2 Hours. \\
\hline Anthrax spore & & $\ldots$ & ... & & + & + & + & + \\
\hline Staphylococcus & pyos & yenes & aurcus & $\ldots$ & + & + & + poor & + slight \\
\hline Streptococcus & yoger & & ... & .. & 0 & 0 & 0 & 0 \\
\hline Controls... & ... & ... & $\ldots$ & .. & + & + & + & + \\
\hline
\end{tabular}

RESUlts.

Iiquid Unconcentrated.

Liquid Reduesed to Half its Rulk

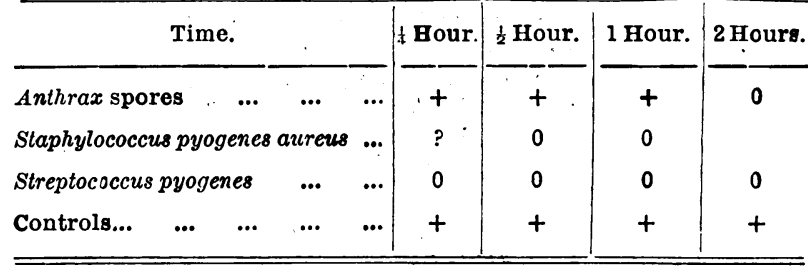

Liquid Reduced to Qwarter Bu'k.

\begin{tabular}{cccc|c|c|c|c}
\hline \multicolumn{2}{c|}{ Time. } & & & $\$$ Hour. & $\frac{1}{2}$ Hour. & 1 Hour. & 2 Hours. \\
\hline Anthrax spores & $\ldots$ & $\ldots$ & $\ldots$ & + & + & 0 & 0 \\
Staphylccoccus pyogenes & aureus & $\ldots$ & 0 & 0 & 0 & 0 \\
Streptococcus pyogenes & $\ldots$ & $\ldots$ & 0 & 0 & 0 & 0 \\
\hline
\end{tabular}


But while the substance of the catgut is thus not onjy aseptlc but powerfully antiseptlc, its dry surface is liable to contamination by contact with septic material, and it is essentlal that; before being used, it be washed with some trustworthy germicldal llquid.

My practlce has' been to put the catgut, like the instruments, in 1 to 20 solution of carbolic acld about a quarter of an hour before the operation is begun. Any of the catgut that remains unueed upon the reel may be afterwards kept in a similar solution for any length of time without disadvantage.

The essential precaution of purifying the surface of the catgut is, I fear, sometimes overlooked, the result belng occasional suppuration attributed to defect in the ligature, while it is really the fault of the anrgeon.

\section{themarks}

ON

\section{THE RESULTS OF THE OPERATIVE TREATMENT OF CHRONIC CONSTIPATION.}

BY W. ARBUTHNOT LANE, M.S.,

SURGEON TO GUY'S HOSPITAL AND TO THE HOSPITAL FOR SICK CHILDREN, GREAT ORMOND STREET.

WHILE the term "chronic constipation" is in the large majority of cases quite correct, yet In a certain number a very advanced condition of antolntoxication may be assoclated with a daily evacuation of the bowel, and also In some of the complications of chronic constipation, such as mucous, membranous, or vlcerative colitis, the motions are usually fluid and frequent.

Again, in a certain proportion of cases of autolntoxication the patlent may have several fluid motions during the day. I Indicate these facts as some apology for the term " chronic constipation" which I have employed, not becanse it is completely comprehensive, but for the reason that it gives the most general idea of what I wish to call attention to.

In the earllest cases In which I removed the greater part of the large bowel the symptom demanding it was pain, usually in the caecum, splentc flexure, or sigmoid. Though I was aware of the associated symptoms of autointorlcatlon I did not operate for thelr removal, nor was I aware that the excision of the large bowel would result in their complete disappearance. I only became conscions of this result after the removal of the large bowel. And the comparatively abrupt change whlch ensued during the few days following the operation was almost startling

The recognitlon of the immense advantages which these miserable people obtained from the removal of the large bowel then induced me to operate also in cases where pain was not necessarily such a marked feature, but where life was becoming a burden through the misery and distress Induced by the autointoxication and Its results. As time went on I found that the condition of chronic Intestinal stasls had a very extensive and far-reaching pathology, part of which was due merely to mechanical canses and part to the Influence exerted by the poison sbsorbed. A greater experience of these cases gerved to increase the range of the knowledge of these effects and to associate with this condition in a causal relationship changes which at first sight would appear to have no connexion whatever with it. Metchnlkoff's work has naturally been of the greatest interest and help in the study of these changes. The most Importsint factors in determining the fatality were that one felt justlfied In exposing to what appeared to be such a severe operation only such patients as were practically dying, and In consequence were not in a condition to bear a surgleal operation of even very moderate severity, and that the time spent in performing the earlier operations was naturally longer than that required after some experience. This class of case is about the worst possible Irom the point of view of the surgeon; while the operation is one of moderate severity the resisting power of the patient is at the lowest ebb. The sufferer has not only one trouble, but inging others, some of which are too advanced to be relieved-by one operation alone. I might allude to the dilatation of the stomach, the presence of ulceration of that organ, the acquired adhesions about the gall bladder, the mobility of the kidneys, the degenerative changes in the breasts, the fixation and probable degenerative changes in the lelt ovary, etc.

The removal of the large bowel alone cannot cure all these conditions; many of them may demand subsequent surglcal interference. For this reason, though in a large number complete relief is obtained by operation, in a amaller proportion of very advanced cases the patient has stlll much lelt to complain of. It Is quite obvions, therefore, that the earlier the patient is deprived of the cause of all these troubles the better is the result.

At first I was satisfied in most cases to remove the large bowel as far as the splenlc flexure, as I belleved that the risk of the operation was reduced by lesving the descending colon and sigmold, for these structures belng vertlcally placed I did not expect that material would accumulate in them above the junction of the lleum and rectum. I found, however, that many of those In whom this portion of the large bowel was left complained, after a lapse of time, of symptoms which I was able to attribute to distension of the descending colon and sigmold with gas. Therefore I excised the residual bowel in many such cases of incomplete resection and took away the entire large bowel with the exception of the rectum in all primary operations.

Constant and prolonged vomiting frequently was a very distressing feature after these operations, and in some cases it was so serious as to imperil the life of the patlent. We found by putting the patient on constant and abundant subcutaneous saline injection all vomiting was done away with, the benefic1al result to the patient of the subcutaneous injection being most striking. Instead of these patients vomiting for days, the large majority do not vomit once after the operation. I am under the impression that abundant subcutaneous infusion also obviates what I have found to be an occasional objectionable complication in very advanced cases, namely, the fixation of the dilated small Intestine by adhesions. These occasionally produce obstruction of the anchored bowel and may call for surgical interference for their liberation. In this way the risks of the operation have been greatly reduced. One mlght say that if the patient is in a condition to bear any sargical operation of moderate severity the removal of the large bowel may be undertaken with the same sense of security.

I do not propose to attempt to prove anything by statistics, as personally I have very little confidence in them, but I will relate briefly the notes of several cases.

\section{Case I.}

F. M. M., aged 36, a nurse, was admitted into Guy's Hospital, under my care, on March 25th, 1907, suffering from an extreme condition of antolntoxication which rendered her quite unfit to continue her occupation. On April 25th the large bowel was removed up to the splenic flexure and the ileum was united to the slomold.

The Improvement which ensued was very rapld. She left the hospital on May 28th, having lost all her symptoms and putting on flesh rapidly. She was delighted with her condition.

8. K., male, aged 19. Operated on In Guy's Hospital in November, 1906. He had been troubled with his bowels from infancy. The reason he was admitted under my care was that for the last six months the pain from which he suffered in the late afternion in his abdomen had become so severe that he was nnable to follow his occupation. The pain was referred to the sigmold, which was telescoped, hard, and tender, and fired in the illac fossa. His skin 'had a most offensive smell, and, although his underclothes were changed frequently, it was distinctly perceptible to others. He was very thin and wasted, and his skin was of a dirty-brown colour. His lips were opague, and he had no reddish tint whatever. Within three days of the operation, which consisted in the removal of the large bowel to the splenic flexure, the offensive smell had disappeared completely, and much of the general pigmentation had gone also. He had also. lost his pain.

In November, 1907, his health was excelient, his appetite was good, hls dirty colour had quite gone, and hls face 